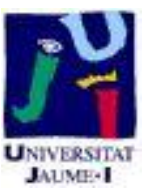

Título artículo / Títol article: A Fast and Precise Method To Identify Indolic Glucosinolates and Camalexin in Plants by Combining Mass Spectrometric and Biological Information

Autores / Autors

Sara Izquierdo Zandalinas, Vicente Vives-Peris, Aurelio Gómez-Cadenas, Vicent Arbona

Revista:

Journal of Agricultural and Food Chemistry, 2012, 60 (35)

Versión / Versió:

Postprint del autor

Cita bibliográfica / Cita bibliogràfica (ISO 690):
IZQUIERDO ZANDALIAS, Sara; VIVESPERIS,Vicente; GÓMEZ-CADENAS, Aurelio; ARBONA, Vicent. A Fast and Precise Method To Identify Indolic Glucosinolates and Camalexin in Plants by Combining Mass Spectrometric and Biological Information. Journal of Agricultural and Food Chemistry, 2012 , vol. 60 , no 35 , p. $8648-8658$.

url Repositori UJI: http://hdl.handle.net/10234/62572 


\title{
A Fast and Precise Method To Identify Indolic Glucosinolates and Camalexin in Plants by Combining Mass Spectrometric and Biological Information
}

\author{
4 Sara Izquierdo Zandalinas, Vicente Vives-Peris, Aurelio Gómez-Cadenas, and Vicent Arbona* \\ 5 Departament de Ciències Agràries i del Medi Natural, Universitat Jaume I, Campus de Riu Sec. Avda, Sos Baynat s/n, E-12071 \\ 6 Castelló de la Plana, Spain
}

7 S Supporting Information

8 ABSTRACT: In this manuscript, a fast and accurate identification and quantitation by mass spectrometry of indolic 9 glucosinolates and camalexin involved in defense in Arabidopsis thaliana are described. Two elicitation systems, inoculation with 10 Botrytis cinerea and treatment with $\mathrm{AgNO}_{3}$, were used in Col-0 wild-type and mutant genotypes impaired in the biosynthesis of 11 the selected metabolites. Identification of analytes was carried out by nontargeted LC/ESI-QTOF-MS profiling. Confirmation of 12 indolic glucosinolates and camalexin was achieved by their absence in the cyp $79 B 2 / B 3$ and pad3 mutants as well as their 13 respective fragmentation upon collision-induced dissociation. Camalexin accumulation was induced only after $\mathrm{AgNO}_{3}$ treatment, 14 whereas all indolic glucosinolates were constitutively present. Inoculation with Botrytis did not influence camalexin concentration 15 but caused most aliphatic and indolic glucosinolates contents to decrease. Only the pen 3.1 mutant showed increased indolic 16 glucosinolate levels after Botrytis or $\mathrm{AgNO}_{3}$ treatments. In addition, profiles of secondary metabolite in nontreated Col-0 and 17 mutant plants were analyzed by means of partial least squares coupled to discriminant analysis (PLS-DA), and differences in the 18 basal levels of indolic glucosinolates and tryptophan between cyp79B2/B3 plants and the rest of genotypes, including Col-0, were 19 found. This probably has to be taken into consideration when comparing stress responses of Col-0 and cyp79B2/B3. The use of 20 mutants carrying alterations in biosynthetic pathways is proposed as a useful strategy to identify secondary metabolites.

21 KEYWORDS: metabolomics, LC/ESI-QTOF-MS, abiotic stress, biotic stress, secondary metabolism, phytoalexins

\section{INTRODUCTION}

23 In response to environmental stress conditions, plants activate a 24 plethora of responses including changes in growth and 25 developmental patterns and primarily severe alterations in 26 metabolic processes such as glycolysis, tricarboxylic acid cycle, 27 and aminoacid biosynthesis. ${ }^{1,2}$ Abiotic stress conditions, such as 28 drought or salinity, directly affect carbon assimilation and 29 consequently alter plant primary metabolism. ${ }^{2,3}$ It has been 30 shown that the stress conditions also affect the accumulation of 31 different minor compounds with a less clear interconnection 32 with photosynthesis. ${ }^{4,5}$ These compounds, collectively referred 33 to as secondary metabolites, are of very diverse origins, and 34 their composition and biosynthesis are not yet well understood. 35 Their biological roles are also very diverse and include 36 antioxidant properties, defense, or signaling. ${ }^{6-8}$ Interestingly, 37 they are specific for given species or botanical families. 38 Therefore, these compounds could be used as markers to 39 certify plant material from different origins, ${ }^{9}$ an important 40 aspect when dealing with many species of importance to human 41 nutrition and health.

42 Among all edible plants, Brassicaceae is the botanical family 43 including more species important in agriculture and human 44 nutrition, for example, cabbage, turnip, rapeseed, etc. 45 Glucosinolates, the most abundant compounds of this family, 46 are sulfur- and nitrogen-containing molecules that carry a 47 hydroxyaminosulfate group and $\beta$-thioglucosyl residue attached 48 to a variable side chain. ${ }^{10}$
Glucosinolates are synthesized from aminoacids by con- 49 version to the respective acetaldoxime derivative by cyto- 50 chromes (CYP79F1/F2 and CYP79B2/B3, Figure 1, adapted $51 \mathrm{fl}$ from ref 11). Depending on the side chain, glucosinolates can 52 be divided into aliphatic (derived from alanine, methionine, 53 valine, or leucine), aromatic (derived from tyrosine or 54 phenylalanine), and indolic (which are mainly derived from 55 tryptophan). ${ }^{11,12}$ These compounds have been primarily 56 associated with defense against biotic stressors such as 57 herbivores, fungi, and also bacteria acting as growth deterrents 58 or as powerful toxic substances. To exert their biological 59 activity, the $\beta$-thioglucosyl residue needs to be cleaved by a 60 specific enzyme known as myrosinase, a type of thioglycosidase. 61 This enzyme cleaves the $\beta$-thioglycosidic bond, yielding mainly 62 isothiocyanates, thiocyanates, and nitriles, which are responsible 63 for the biological activity of glucosinolates. ${ }^{12,13}$

Among all known glucosinolates (more than 120 structures 65 characterized so far), the indolics are the most important 66 involved in stress defense. ${ }^{12-14}$ In the model plant species, 67 Arabidopsis thaliana, these metabolites are derived from 68 tryptophan after cleavage with a CYP79 enzyme that converts 69 the precursor tryptophan to indole-3-acetaldoxime. This 70 metabolite is the primary precursor of both indolic 71

Received: June 7, 2012

Revised: August 6, 2012

Accepted: August 8, 2012 

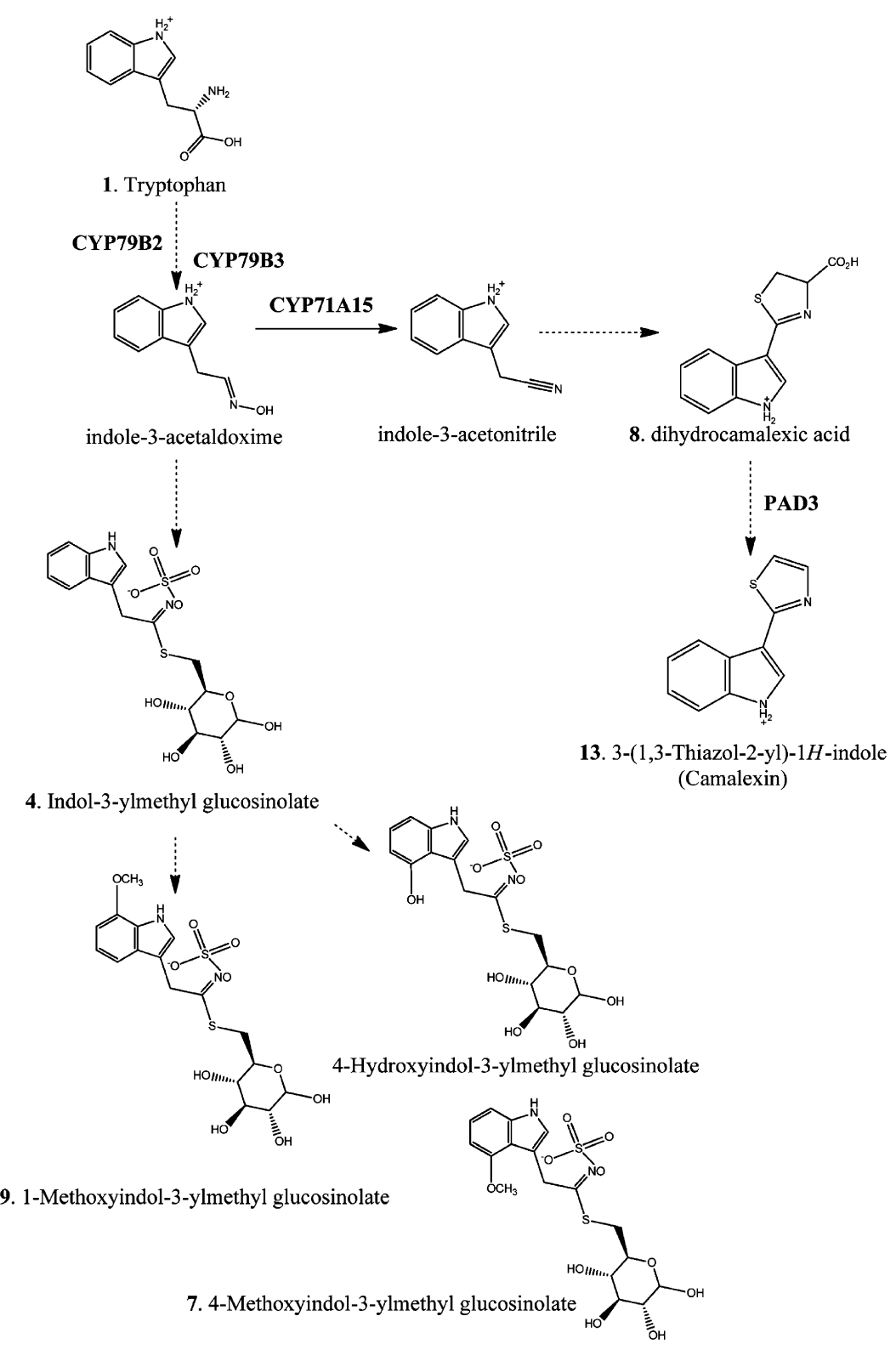

Figure 1. Metabolic pathway of indolic glucosinolates with names of key biosynthetic steps highlighted. The compounds detected in the profiles are indicated in Arabic numerals. The scheme was adapted from ref 11.

72 glucosinolates and camalexin [3-(1,3-thiazol-2-yl)-1H-indole], 73 the main phytoalexin. Indolic glucosinolates are always present 74 in plant tissues, although their relative levels might change 75 depending on the specific genetic background, tissue or 76 developmental stage, ${ }^{14}$ and in response to environmental 77 cues. $^{14,15}$ On the contrary, phytoalexins are only produced 78 under certain stress conditions, such as pathogen elicitation, 79 heavy metal toxicity, etc. ${ }^{6}$ In this sense, it is likely that the 80 production of glucosinolates in A. thaliana under certain stress 81 conditions is tightly regulated. ${ }^{16,17}$

82 Stress responses might reflect whole plant performance, 83 physiological status, or even a genetic modification. Therefore, 84 there is an increasing demand for high-throughput methods to 85 evaluate slight variations in minor compounds. ${ }^{4,9}$ In this sense, $86 \mathrm{LC} / \mathrm{MS}$-based metabolite profiling techniques provide an 87 unbiased methodology for the analysis of semipolar com88 pounds. ${ }^{9,18}$ Current metabolite profiling platforms take 89 advantage of modern mass spectrometers (as well as other powerful techniques, such as NMR) to gather molecular 90 information on metabolites to aid in structural elucidation and 91 identification. However, mass spectrometry is not enough to 92 identify all metabolites present in a given sample, and it 93 becomes necessary to coinject reference standards, which are 94 not always commercially available. In addition, in the analysis of 95 intact glucosinolates, it is crucial to first suppress all myrosinase 96 activity by boiling the samples to prevent cleavage to take 97 place. ${ }^{19}$

In metabolite profiling techniques, a bottleneck is the 99 identification of metabolites. In high-resolution mass spectrom- 100 etry, such as hybrid quadrupole time-of-flight (QTOF), 101 identification of metabolites starts by formulating a hypothesis 102 on the identity of a metabolite based on the ion composition of 103 the mass chromatographic feature, search of informative 104 fragmentations, and calculation of elemental composition. 105 However, the unbiased identification of a certain metabolite 106 is limited to the commercial availability of analytical stand- 107 
108 ards. ${ }^{18}$ This is of special relevance in the case of indolic 109 glucosinolates, for which no commercial standards are 110 available. ${ }^{19}$ To overcome this problem, a set of Arabidopsis 111 mutants lacking different key enzymes in indolic glucosinolate 112 or camalexin biosynthesis were included in this study. In 113 addition, two different adverse conditions were assayed: biotic 114 stress by inoculating plants with Botrytis cinerea conidia, a 115 necrotrophic fungal plant pathogen to which $A$. thaliana has 116 developed a nonhost resistance, ${ }^{20}$ and abiotic stress by spraying 117 plants with a $\mathrm{AgNO}_{3}$ solution, which induces the accumulation 118 of camalexin. ${ }^{20,21}$

119 In this work, the main objective was to unequivocally identify 120 indolic glucosinolates and camalexin in Arabidopsis plants by 121 using the biological information obtained from mutants 122 impaired in the biosynthesis of these compounds. In addition, 123 the impact of biotic and abiotic stress on glucosinolate and 124 camalexin accumulation and the difference in metabolite 125 composition among Arabidopsis mutants and wild-type plants 126 were analyzed.

\section{MATERIALS AND METHODS}

128 Reagents and Standards. Liquid chromatography-mass spec129 trometry (LC-MS) grade acetonitrile from Panreac (Barcelona, Spain) 130 and Milli-Q water (Millipore Corp., Billerica, MA) were used for the 131 liquid chromatography/electrospray ionization-quadrupole time-of132 flight mass spectrometry (LC/ESI-QTOF-MS) analyses. Formic acid 133 (Panreac) was used as the mobile phase modifier. For extractions, 134 methanol (MeOH LC-MS grade) from Panreac was used. Biochanin A 135 (5,7-dihydroxy-4'-methoxyisoflavone) and leucine-enkephalin were 136 obtained from Sigma-Aldrich (Madrid, Spain). For stress treatments 137 and Botrytis culture, $\mathrm{AgNO}_{3}$ and $\mathrm{KH}_{2} \mathrm{PO}_{4}$ were purchased from 138 Panreac.

139 Plant Cultivation and Stress Treatments. Plant material used in 140 the experiments was $A$. thaliana accessions Col- 0 as wild type and 141 mutants pad $3,{ }^{22,23}$ cyp $79 B 2 / B 3,{ }^{24}$ and pen $3.1,{ }^{20}$ all in the Col-0 142 background. Seeds were germinated in jiffy pellets (Jiffy Products 143 España S.L.U., Murcia, Spain) and allowed to grow for 2 weeks in a 144 growth chamber with $8 \mathrm{~h}$ of illumination at $21^{\circ} \mathrm{C}$ and $16 \mathrm{~h}$ of darkness 145 at $18{ }^{\circ} \mathrm{C}$. After that time, seedlings were transplanted to individual jiffy 146 pellets and allowed to grow for 6 more weeks before imposition of 147 treatments. For abiotic and biotic stress treatments, plants were 148 sprayed with a $5 \mathrm{mM} \mathrm{AgNO}$ solution or with a $B$. cinerea conidia 149 suspension $\left(5 \times 10^{4}\right.$ conidia/mL in Gamborg medium, supplemented 150 with $10 \mu \mathrm{mol} / \mathrm{L}$ sucrose and $\mathrm{KH}_{2} \mathrm{PO}_{4}$, as described in ref 25). Control 151 plants were sprayed with tap water. After $24 \mathrm{~h}$ of each treatment, leaf 152 rosettes of the different genotypes were harvested, immediately frozen 153 in liquid nitrogen, ground to fine powder, and stored at $-80{ }^{\circ} \mathrm{C}$ until 154 analysis. Two independent biological replicate experiments were 155 performed, and three independent sample replicates per sample group 156 and experiment were analyzed by LC/ESI-QTOF-MS.

157 Extraction. Extraction was performed essentially as previously 158 described in ref 19 with slight modifications. Briefly, $500 \mu \mathrm{L}$ of $70 \%$ 159 methanol supplemented with biochanin $\mathrm{A}$ at $1 \mathrm{mg} / \mathrm{L}$ (internal 160 standard, IS) was added to $0.1 \mathrm{~g}$ of frozen leaf powder. After $10 \mathrm{~min}$ of 161 sonication, samples were incubated for $15 \mathrm{~min}$ at $80^{\circ} \mathrm{C}$ in a water bath 162 to stop myrosinase activity. Extracts were allowed to cool down at 163 room temperature and centrifuged at $10000 \mathrm{~g}$ for $10 \mathrm{~min}$ at $4{ }^{\circ} \mathrm{C}$. Prior 164 to UPLC-QTOF-MS analysis, supernatants were filtered through 0.2 $165 \mu \mathrm{m}$ PTFE syringe filters (Whatman International Inc., Kent, United 166 Kingdom).

167 Instrumentation and Conditions. Chromatographic separations 168 were performed on an Acquity SDS system (Waters Corp. Ltd., 169 Milford, MA) interfaced to a QTOF Premier from Micromass Ltd. 170 through an ESI source. Two reversed-phase columns were evaluated as 171 follows: $100 \mathrm{~mm} \times 2.1 \mathrm{~mm}$ i.d., $5 \mu \mathrm{m}$, XTerra C18 LC-MS (Waters), 172 and $100 \mathrm{~mm} \times 2.1 \mathrm{~mm}$ i.d., $2.1 \mu \mathrm{m}$, ProntoSIL C18SH (Bischoff 173 Chromatography, Leonberg, Germany). Samples were injected in the
UPLC system in $10 \mu \mathrm{L}$ aliquots using the partial loop-filling option. 174 Separations were carried out using two gradients at a flow rate of 300175 $\mu \mathrm{L} / \mathrm{min}$. Conditions of gradient 1 were as follows: $0-2 \mathrm{~min}$, isocratic 176 95\% A [water:formic acid, 99.9:0.1 (v/v)] and 5\% B [acetonitrile:- 177 formic acid, 99.9:0.1 (v/v)]; 2-27 min, gradient 5-95\% B; 27-30 178 min, return to initial conditions; 30-35 min, re-equilibration period. 179 Conditions of gradient 2 were as follows: $0-2 \mathrm{~min}$, isocratic 5\% B; 2- 180 $17 \mathrm{~min}$, gradient $5-95 \% \mathrm{~B} ; 17-20 \mathrm{~min}$, return to initial conditions; 181 20-25 min, re-equilibration period. During analyses, the column 182 temperature was maintained at $40{ }^{\circ} \mathrm{C}$, and samples were maintained at 183 $5{ }^{\circ} \mathrm{C}$ to slow down degradation.

Samples were analyzed in both negative and positive ionization 185 modes. Two functions were set in the instrument: in function 1, data 186 were acquired in profile mode from 50 to $1000 \mathrm{Da}$ using a scan time of 187 $0.2 \mathrm{~s}$ and a collision energy of $2 \mathrm{eV}$; in function 2, the scan range was 188 the same, but a collision ramp between 4 and $65 \mathrm{eV}$ was set. During all 189 measurements, the electrospray capillary voltage was set to $4 \mathrm{kV}$, and 190 the cone voltage was set to $25 \mathrm{~V}$. The source temperature was 191 maintained at $120{ }^{\circ} \mathrm{C}$, and the desolvation gas temperature was set at 192 $350{ }^{\circ} \mathrm{C}$. Argon was used as the collision gas, and nitrogen was used as 193 the nebulizer as well as desolvation gas set at 60 and $800 \mathrm{~L} / \mathrm{h}, 194$ respectively. Exact mass measurements were provided by monitoring 195 the reference compound lockmass leucine-enkephalin.

196

Data Processing. Data were processed using Masslynx v.4.1. Raw 197 data files were converted to netCDF format using the application 198 databridge from Masslynx and processed using the xcms package. ${ }^{26}{ }_{199}$ Chromatographic peak detection was performed using the match- 200 edFilter algorithm, ${ }^{9}$ applying the following parameter settings: $\mathrm{snr}=3,201$ fwhm $=15 \mathrm{~s}$, step $=0.01 \mathrm{D}$, mzdiff $=0.1 \mathrm{D}$, and profmethod $=$ bin. 202 Retention time correction was achieved in three iterations applying the 203 parameter settings minfrac $=1, \mathrm{bw}=30 \mathrm{~s}$, mzwid $=0.05 \mathrm{D}$, $\mathrm{span}=1,204$ and missing $=$ extra $=1$ for the first iteration; $\operatorname{minfrac}=1$, bw $=10 \mathrm{~s}, 205$ mzwid $=0.05 \mathrm{D}$, span $=0.6$, and missing $=$ extra $=0$ for the second 206 iteration; and minfrac $=1, \mathrm{bw}=5 \mathrm{~s}$, mzwid $=0.05 \mathrm{D}$, span $=0.5$, and 207 missing $=$ extra $=0$ for the third iteration. After final peak grouping 208 $(\operatorname{minfrac}=1, \mathrm{bw}=5 \mathrm{~s})$ and filling in of missing features using the 209 fillPeaks routine of the $\mathrm{xcms}$ package, a data matrix consisting on 210 feature $\times$ sample was obtained. In these data sets, only consistent mass 211 signals were considered, whose significance level of $P$ values $(t$ test, 212 two-tailed, unequal variances) was lower than 0.05 .

213

Data mean comparisons were performed with Statgraphics Plus 214 V.5.1. software (Statistical Graphics Corp., Herndon, VA). One-way 215 analysis of variance (ANOVA) was performed to assess differences 216 between treatments and genotypes considering a significance value of 217 0.05. Posthoc data mean comparisons were achieved with a least 218 significant difference (LSD) test. For multivariate analysis of the whole 219 data set, peak detection and retention time correction of control 220 samples of each genotype were performed using a similar set of 221 parameters as described above. After filling in missing chromato- 222 graphic mass features and removal of inconsistent features, principal 223 component analysis (PCA) and partial least-squares discriminant 224 analysis (PLS-DA) were performed using Simca-P (v 11.0) software 225 (Umetrics, Umea, Sweden).

226

RESULTS AND DISCUSSION

Optimization of Chromatography. Until now, few 228 studies have described the use of UPLC-MS for the analysis 229 of glucosinolates and camalexin. Recently, a new powerful 230 identification tool has become available: the hybrid QTOF 231 mass spectrometer. In addition to the improved characteristics 232 of TOF instruments, they offer the possibility of performing 233 MS/MS acquisitions to obtain product ion spectra with 234 accurate mass, which is sometimes necessary to aid in the 235 identification of compounds or even differentiate between 236 structural isomers. $^{22,27}$

In this first part of this work, the objective was to develop a 238 nontargeted metabolite profiling methodology for the analysis 239 of variations in indolic glucosinolate and camalexin levels in A. 240 
Table 1. List of Metabolites Identified in Arabidopsis Leaf Extracts ${ }^{a}$

\begin{tabular}{|c|c|c|c|c|c|c|c|c|}
\hline \multirow[b]{2}{*}{ no. } & \multirow[b]{2}{*}{ compd name } & \multirow[b]{2}{*}{ formula } & \multirow{2}{*}{$\begin{array}{c}\text { quantifier ion } \\
\text { type, } m / z\end{array}$} & \multirow{2}{*}{$\begin{array}{c}R_{\mathrm{t}} \\
(\mathrm{min})\end{array}$} & \multicolumn{3}{|c|}{ pseudomolecular ion } & \multirow[b]{2}{*}{ CID fragmentation ${ }^{b}$} \\
\hline & & & & & ion type & theor $m / z$ & $\operatorname{exptl} m / z$ & \\
\hline 1 & tryptophan & $\mathrm{C}_{11} \mathrm{H}_{12} \mathrm{~N}_{2} \mathrm{O}_{2}$ & {$[\mathrm{M}+\mathrm{H}]^{+} 205.09$} & 4.03 & $\begin{array}{c}{[\mathrm{M}+} \\
\mathrm{H}]^{+} \\
{[\mathrm{M}-} \\
\mathrm{H}]^{-}\end{array}$ & $\begin{array}{l}205.0977 \\
203.08205\end{array}$ & $\begin{array}{l}205.0997 \\
203.0774\end{array}$ & $\begin{array}{l}205,188,146,118,91 \\
203,142,116,74\end{array}$ \\
\hline 2 & 4-methylthiobutyl glucosinolate & $\mathrm{C}_{12} \mathrm{H}_{23} \mathrm{NO}_{9} \mathrm{~S}_{3}$ & {$[\mathrm{M}-\mathrm{H}]^{-} 420.05$} & 3.89 & $\begin{array}{l}{[\mathrm{M}+\mathrm{K}]^{+}} \\
{[\mathrm{M}-} \\
\mathrm{H}]^{-}\end{array}$ & $\begin{array}{l}460.0172 \\
420.0456\end{array}$ & $\begin{array}{l}460.0112 \\
420.0459\end{array}$ & $\begin{array}{l}\text { 460, 342, 238, } 192 \\
420,259,178,96\end{array}$ \\
\hline 3 & 7-methylsulfinylheptyl glucosinolate & $\mathrm{C}_{15} \mathrm{H}_{29} \mathrm{NO}_{10} \mathrm{~S}_{3}$ & {$[\mathrm{M}-\mathrm{H}]^{-} 478.09$} & 3.87 & $\begin{array}{l}{[\mathrm{M}+\mathrm{K}]^{+}} \\
{[\mathrm{M}-} \\
\mathrm{H}]^{-}\end{array}$ & $\begin{array}{l}518.05906 \\
478.08753\end{array}$ & $\begin{array}{l}518.0777 \\
478.0866\end{array}$ & $\begin{array}{l}\mathbf{5 1 8}, 298 \\
\mathbf{4 7 8}, 259,96\end{array}$ \\
\hline 4 & indol-3-ylmethyl glucosinolate & $\mathrm{C}_{16} \mathrm{H}_{18} \mathrm{~N}_{2} \mathrm{O}_{9} \mathrm{~S}_{2}$ & {$[\mathrm{M}-\mathrm{H}]^{-} 447.06$} & 4.41 & $\begin{array}{l}- \\
{[\mathrm{M}-} \\
\mathrm{H}]^{-}\end{array}$ & $\begin{array}{c}- \\
447.05319\end{array}$ & $\begin{array}{c}- \\
447.0525\end{array}$ & $\begin{array}{l}- \\
447,96\end{array}$ \\
\hline 5 & 8-methylsulfinyloctyl glucosinolate & $\mathrm{C}_{16} \mathrm{H}_{31} \mathrm{NO}_{10} \mathrm{~S}_{3}$ & {$[\mathrm{M}-\mathrm{H}]^{-} 492.10$} & 4.74 & $\begin{array}{c}{[\mathrm{M}+} \\
\mathrm{Na}]^{+} \\
{[\mathrm{M}-} \\
\mathrm{H}]^{-}\end{array}$ & $\begin{array}{r}516.10077 \\
492.10318\end{array}$ & 516.094 & $\begin{array}{l}\text { 516, 414, 252, } 96 \\
492,428,96\end{array}$ \\
\hline 6 & 5-methylthiopentyl glucosinolate & $\mathrm{C}_{13} \mathrm{H}_{25} \mathrm{NO}_{9} \mathrm{~S}_{3}$ & {$[\mathrm{M}-\mathrm{H}]^{-} 434.06$} & 5.01 & $\begin{array}{l}- \\
\mathrm{H}]^{-}\end{array}$ & $\begin{array}{c}- \\
434.06132\end{array}$ & $\begin{array}{c}- \\
434.0618\end{array}$ & $\begin{array}{l}- \\
434,96\end{array}$ \\
\hline 7 & 4-methoxyindol-3-ylmethyl glucosinolate & $\mathrm{C}_{17} \mathrm{H}_{22} \mathrm{~N}_{2} \mathrm{O}_{10} \mathrm{~S}_{2}$ & {$[\mathrm{M}-\mathrm{H}]^{-} 477.06$} & 5.21 & $\begin{array}{l}{[\mathrm{M}+\mathrm{K}]^{+}} \\
{[\mathrm{M}-} \\
\mathrm{H}]^{-}\end{array}$ & 517.03529 & 517.0386 & $\begin{array}{l}517,479,437,399 \\
237,160 \\
477,96\end{array}$ \\
\hline 8 & dihydrocamalexic acid & $\mathrm{C}_{12} \mathrm{H}_{10} \mathrm{~N}_{2} \mathrm{O}_{2} \mathrm{~S}$ & {$[\mathrm{M}+\mathrm{H}]^{+} 247.05$} & 5.59 & $\begin{array}{c}{[\mathrm{M}+} \\
\mathrm{H}]^{+} \\
-\end{array}$ & $\begin{array}{l}247.05412 \\
-\end{array}$ & $\begin{array}{c}247.0605 \\
-\end{array}$ & $\begin{array}{l}247,201,143,118 \\
-\end{array}$ \\
\hline 9 & 1-methoxyindol-3-ylmethyl glucosinolate & $\mathrm{C}_{17} \mathrm{H}_{22} \mathrm{~N}_{2} \mathrm{O}_{10} \mathrm{~S}_{2}$ & {$[\mathrm{M}-\mathrm{H}]^{-} 477.06$} & 5.91 & $\begin{array}{c}{[\mathrm{M}+} \\
\mathrm{H}]^{+} \\
{[\mathrm{M}-} \\
\mathrm{H}]^{-}\end{array}$ & $\begin{array}{l}479.07941 \\
477.06376\end{array}$ & $\begin{array}{l}479.0876 \\
477.0629\end{array}$ & $\begin{array}{l}479,437,399,237 \\
160 \\
477,44,96\end{array}$ \\
\hline 10 & unknown aliphatic glucosinolate* & $\mathrm{C}_{14} \mathrm{H}_{26} \mathrm{NO}_{9} \mathrm{~S}_{2}$ & {$[\mathrm{M}-\mathrm{H}]^{-} 416.10$} & 6.60 & $\begin{array}{l}- \\
{[\mathrm{M}-} \\
\mathrm{H}]^{-}\end{array}$ & $\begin{array}{c}- \\
416.10489\end{array}$ & $\begin{array}{c}- \\
416.1093\end{array}$ & $\begin{array}{l}- \\
416,389,357,323 \\
\quad 119,96\end{array}$ \\
\hline 11 & 7-methylthioheptyl glucosinolate & $\mathrm{C}_{15} \mathrm{H}_{29} \mathrm{NO}_{9} \mathrm{~S}_{3}$ & {$[\mathrm{M}-\mathrm{H}]^{-} 462.09$} & 6.76 & $\begin{array}{l}- \\
{[\mathrm{M}-} \\
\mathrm{H}]^{-}\end{array}$ & $\begin{array}{c}- \\
462.09261\end{array}$ & $\begin{array}{c}- \\
462.0941\end{array}$ & $\begin{array}{l}- \\
462,96\end{array}$ \\
\hline 12 & 8-methylthiooctyl glucosinolate & $\mathrm{C}_{16} \mathrm{H}_{31} \mathrm{NO}_{9} \mathrm{~S}_{3}$ & {$[\mathrm{M}-\mathrm{H}]^{-} 476.11$} & 7.55 & $\begin{array}{c}{[\mathrm{M}+} \\
\mathrm{H}]^{+} \\
{[\mathrm{M}-} \\
\mathrm{H}]^{-}\end{array}$ & $\begin{array}{l}478.12391 \\
476.10826\end{array}$ & $\begin{array}{l}478.1278 \\
476.1089\end{array}$ & $\begin{array}{l}478,398,236 \\
476,96\end{array}$ \\
\hline 13 & $\begin{array}{l}\text { 3-(1,3-thiazol-2-yl)-1H-indole } \\
\text { (camalexin) }\end{array}$ & $\mathrm{C}_{11} \mathrm{H}_{8} \mathrm{~N}_{2} \mathrm{~S}$ & {$[\mathrm{M}+\mathrm{H}]^{+} 201.05$} & 8.91 & $\begin{array}{c}{[\mathrm{M}+} \\
\mathrm{H}]^{+} \\
{[\mathrm{M}-} \\
\mathrm{H}]^{-}\end{array}$ & $\begin{array}{r}201.04864 \\
199.03299\end{array}$ & 201.0517 & $\begin{array}{l}201,174,160,142,59 \\
199,158,141,130\end{array}$ \\
\hline 14 & $\begin{array}{l}\text { 5,7-dihydroxy-4'-methoxy-isoflavone } \\
\text { (biochanin A)** }\end{array}$ & $\mathrm{C}_{16} \mathrm{H}_{12} \mathrm{O}_{5}$ & {$[\mathrm{M}+\mathrm{H}]^{+} 285.07$} & 10.93 & $\begin{array}{c}{[\mathrm{M}+} \\
\mathrm{H}]^{+} \\
{[\mathrm{M}-} \\
\mathrm{H}]^{-}\end{array}$ & $\begin{array}{l}285.07629 \\
283.06065\end{array}$ & $\begin{array}{l}285.0773 \\
283.0594\end{array}$ & $\begin{array}{l}285,270,242,213 \\
152,124 \\
283,268,239,211 \\
132\end{array}$ \\
\hline
\end{tabular}

${ }^{a}$ Note: dashes (-) denote missing ions, or when expected, pseudomolecular ions or adducts could not be identified. Rt, retention time; *, tentative annotation; and $* *$, internal standard. ${ }^{b}$ Numbers in bold represent precursor ions.

241 thaliana. Therefore, it had to be possible to unequivocally 242 identify these metabolites in plant extracts. As reported 243 previously, ${ }^{18}$ reversed phase liquid chromatography is the best 244 suited technique for the analysis of secondary metabolites in 245 Arabidopsis. In this project, two C18 columns were assayed, a 246 XTerra C18 and a ProntoSIL C18SH. Samples of stressed A. 247 thaliana plants were analyzed in triplicate by using also two 248 gradients. As expected, the XTerra column tested with either 249 gradient 1 or gradient 2 gave worse resolution than ProntoSIL $250 \mathrm{C} 18 \mathrm{SH}$ due to the higher particle size, although all considered 251 metabolites could be detected. Using gradient 2, the total 252 chromatographic run took about $20 \mathrm{~min}$, and all glucosinolates and camalexin eluted in less than $11 \mathrm{~min}$, and using gradient 1, 253 the total chromatographic run took $30 \mathrm{~min}$, and the metabolites 254 of interest eluted within 15 min.

After the chromatographic analysis, peaks were extracted and 256 aligned using $\mathrm{xcms}$ software. The number of peaks obtained 257 was taken as an estimate of the performance of the column. In 258 both cases, samples analyzed with the ProntoSIL C18SH 259 column rendered a higher number of aligned mass features than 260 the same samples analyzed with XTerra C18 LC-MS. The use 261 of the short gradient implied losing 12.2 and $5.3 \%$ of the total 262 peaks in positive and negative mode, respectively. This was 263 considered acceptable taking into consideration the time (10 264 
<smiles>CSCCCC/C(=N/OS(=O)(=O)[O-])SC1OC(CO)C(O)C(O)C1O</smiles>

2. 4-Methylthiobutyl glucosinolate<smiles>CS(=O)CCCCCCC/C(=N\OS(=O)(=O)[O-])SC1OC(CO)C(O)C(O)C1O</smiles>

3. 7-Methylsulphinylheptyl glucosinolate<smiles>CS(=O)CCCCCCCC/C(=N\OS(=O)(=O)[O-])SC1OC(CO)C(O)C(O)C1O</smiles>

5. 8-Methylsulphinyloctyl glucosinolate<smiles>CSCCCCC/C(=N/OS(=O)(=O)[O-])SC1OC(CO)C(O)C(O)C1O</smiles>

6. 5-Methylthiopentyl glucosinolate<smiles>CSCCCCCCC/C(=N/OS(=O)(=O)[O-])SC1OC(CO)C(O)C(O)C1O</smiles>

11. 7-Methylthioheptyl glucosinolate<smiles>CSCCCCCCCC/C(=N/OS(=O)(=O)O)SC1OC(CO)C(O)C(O)C1O</smiles>

12. 8-Methylthiooctyl glucosinolate

Figure 2. Structures of detected aliphatic glucosinolates.

$265 \mathrm{~min}$ ) saved in each analysis. Therefore, in the following 266 analyses, the short gradient was chosen along with the 267 ProntoSIL C18SH column.

268 Identification of Glucosinolates and Camalexin in 269 Stressed Arabidopsis Mutants. The capability of QTOF-MS 270 to measure masses with high accuracy makes this platform a 271 suitable tool to perform nontargeted analysis. Therefore, 272 characteristic fragmentation patterns allow the identification 273 of glucosinolates and camalexin with a high degree of 274 confidence without having to use pure standards. In the 275 present study, typical fragmentation patterns were used to 276 identify glucosinolates and camalexin. Moreover, the biological 277 information of Arabidopsis mutants (pad3, pen3.1, and 278 cyp79B2/B3) as well as Col-0 accessions contributed to the unequivocal identification of the analytes considered in this 279 study. Ten glucosinolates, camalexin, and other related 280 compounds were identified (Table 1).

Compounds 4, 7, and 9 were annotated as indolic 282 glucosinolates, whereas compounds 2, 3, 5,6, 11, and 12283 (Table 1) were tentatively annotated as aliphatic glucosinolates. $284 \mathrm{fz}$ On the basis of recent literature, ${ }^{19}$ compound 10 was also 285 tentatively annotated as an aliphatic glucosinolate with seven 286 carbons in a linear or branched chain, the extent of which could 287 not be properly determined with mass spectrometry data. With 288 the chromatographic conditions used in this work, it was not 289 possible to properly retain other previously reported aliphatic 290 glucosinolates such as 3-methylsulfinylpropyl, 5-methylsulfinyl- 291 pentyl, and 6-methylsulfinylhexyl. However, the methodology 292 

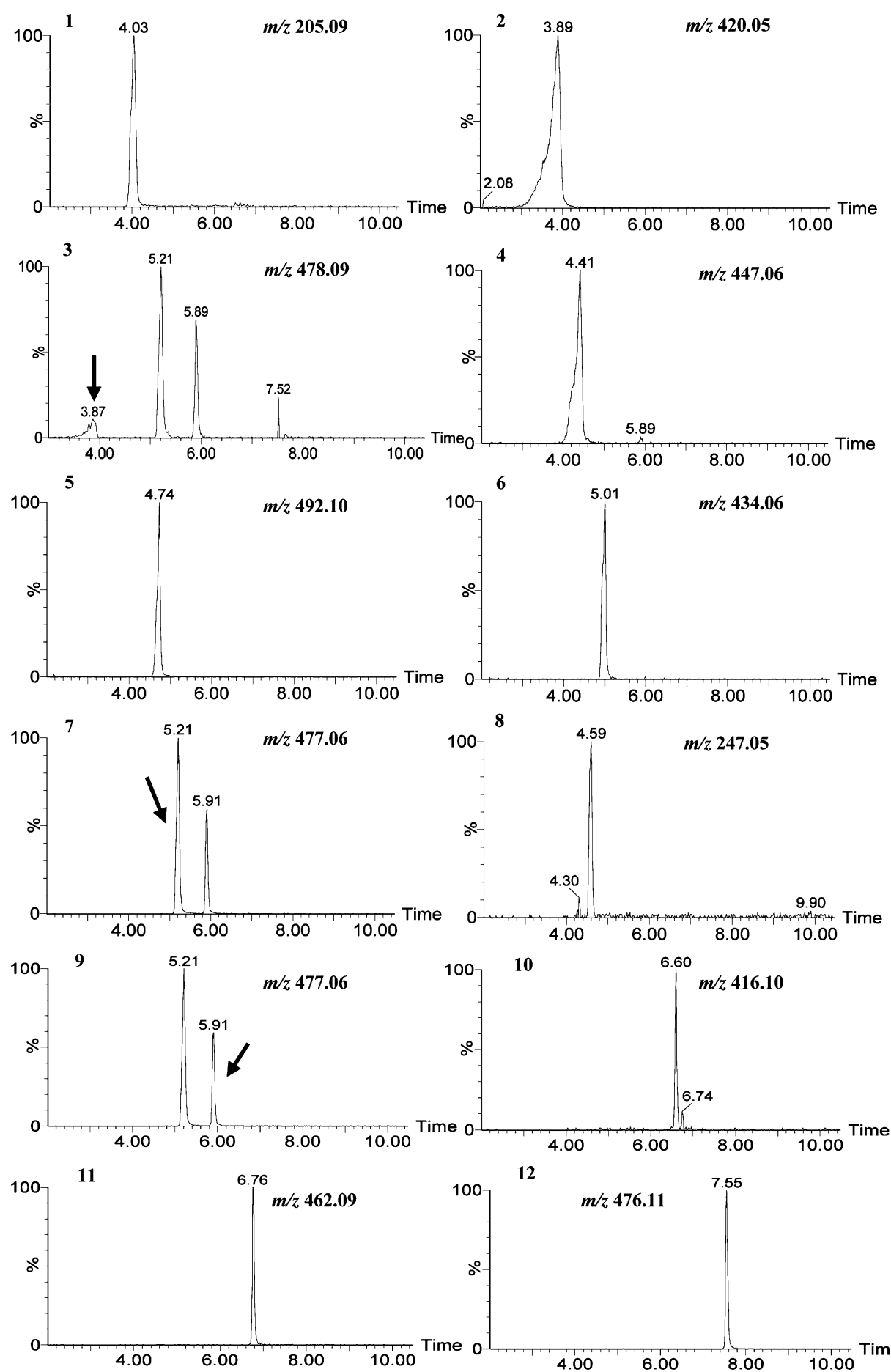

12
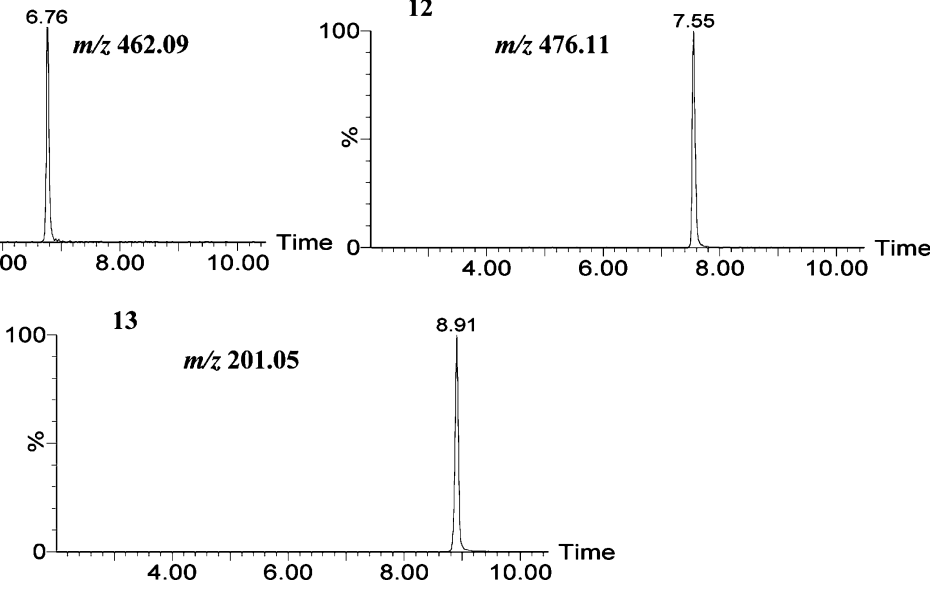

Figure 3. Extracted ion chromatograms for the 10 identified glucosinolates and camalexin. Values within each chromatogram represent $m / z$ used for the extracted ion chromatogram.

293 proved to be sufficient to profile indolic glucosinolates. Related 294 metabolites such as tryptophan (1) and dihydrocamalexic acid 295 (8) were identified and annotated based on biological as well as mass spectrometric data. Extracted ion chromatograms for each 296 compound are shown in Figure 3. As observed in chromato- $297 \mathrm{f3}$ grams, both compounds 7 and 9 showed a maximum at 477.06298 
$\mathbf{A}$

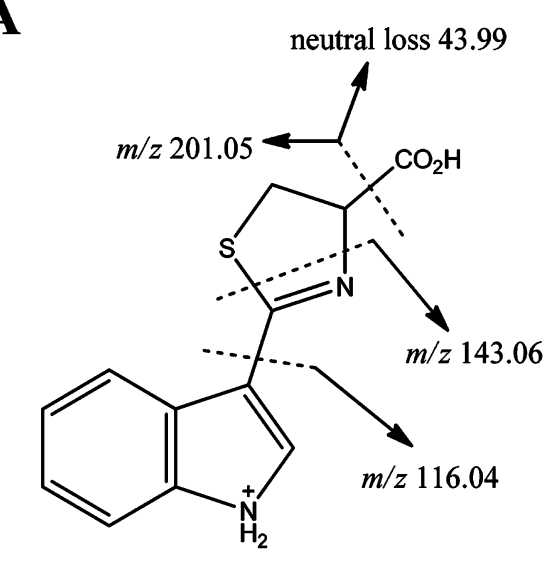

B

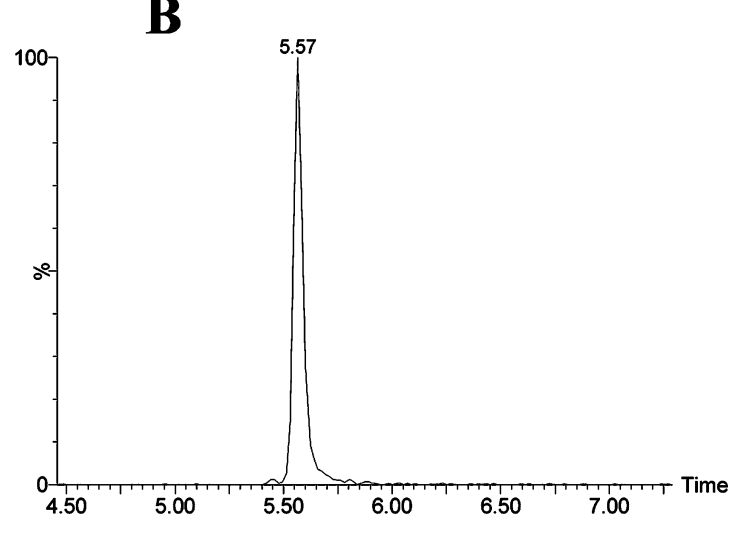

Chemical Formula: $\mathrm{C}_{12} \mathrm{H}_{11} \mathrm{~N}_{2} \mathrm{O}_{2} \mathrm{~S}^{+}$

Exact Mass: 247.0536

$\mathbf{C}$
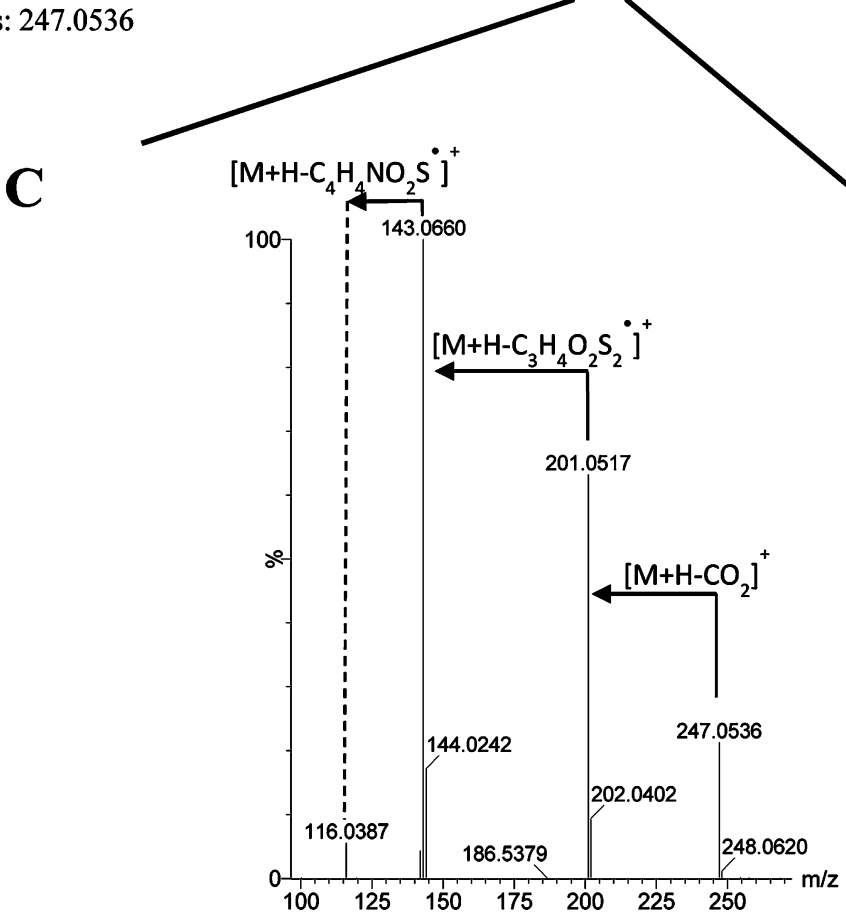

Figure 4. Identification of dihydrocamalexic acid by mass spectrometry: fragmentation pattern of dihydrocamalexic acid (A), chromatographic peak of ddihydrocamalexic acid (B), and fragment ions observed upon collision-induced dissociation (C).

299 corresponding to the $[\mathrm{M}-\mathrm{H}]^{-}$of 4-methoxyindol-3-ylmethyl 300 glucosinolate and the 1-methoxy isomer, respectively. Identi301 fication of each of the isomers was accomplished by their 302 elution order. ${ }^{19}$

303 Characteristic fragmentation patterns were analyzed to 304 confirm the identity of each compound. Table 1 shows the 305 main fragments obtained from each extracted ion chromato306 gram from function 2 acquisition. The characteristic fragment 307 peak at $\mathrm{m} / z 96.96$ was observed in all recorded glucosinolate 308 spectra representing a bisulphate anion $\left(\mathrm{HSO}_{4}{ }^{-}\right)$released after 309 cleavage of intact glucosinolates. A chromatographic peak 310 eluting at $2.0 \mathrm{~min}$ with a $\mathrm{m} / \mathrm{z}$ of 463.05 compatible with the 311 pseudomolecular ion $\left([\mathrm{M}-\mathrm{H}]^{-}\right)$from 4-hydroxyindol-3312 ylmethyl glucosinolate was observed, although its identity could 313 not be properly confirmed due to the low signal intensity 314 shown that rendered a poor fragmentation in function 2 .

315 To verify these results, leaf extracts of stressed Arabidopsis 316 cyp79B2/B3 plants were analyzed by mass spectrometry. The
cyp79B2/B3 double mutant is a hybrid between two lines 317 identified in a loss-of-function screening on a T-DNA insertion 318 collection of the Col-0 ecotype. The T-DNA insertions disrupt 319 their respective genes, rendering null alleles ${ }^{24}$ and plants devoid 320 in any indolic glucosinolate or camalexin. ${ }^{22}$ In the original 321 article $^{24}$ the authors reported subtle phenotype differences 322 between cyp79B2/B3 double mutant and its respective wild- 323 type Col-0; however, under the growth conditions used in this 324 study, both sets of plants were completely indistinguishable 325 (data not shown). As expected, indolic glucosinolates (4, 7, and 326 9) were not detected in any of these samples, whereas aliphatic 327 glucosinolates (2, 3, 5, 6, and 10-12) were detected in 328 cyp79B2/B3 extracts. Arabidopsis pad3, isolated from an 329 ethylmethanesulfonate mutant population, ${ }^{23}$ carries a single 330 nucleotide deletion, leading to an early stop codon in the 331 predicted open reading frame that originates truncated mRNA, 332 which is not translated into a functional CYP71B15 enzyme 333 (that converts dihydrocamalexic acid into camalexin). Corre- 334 

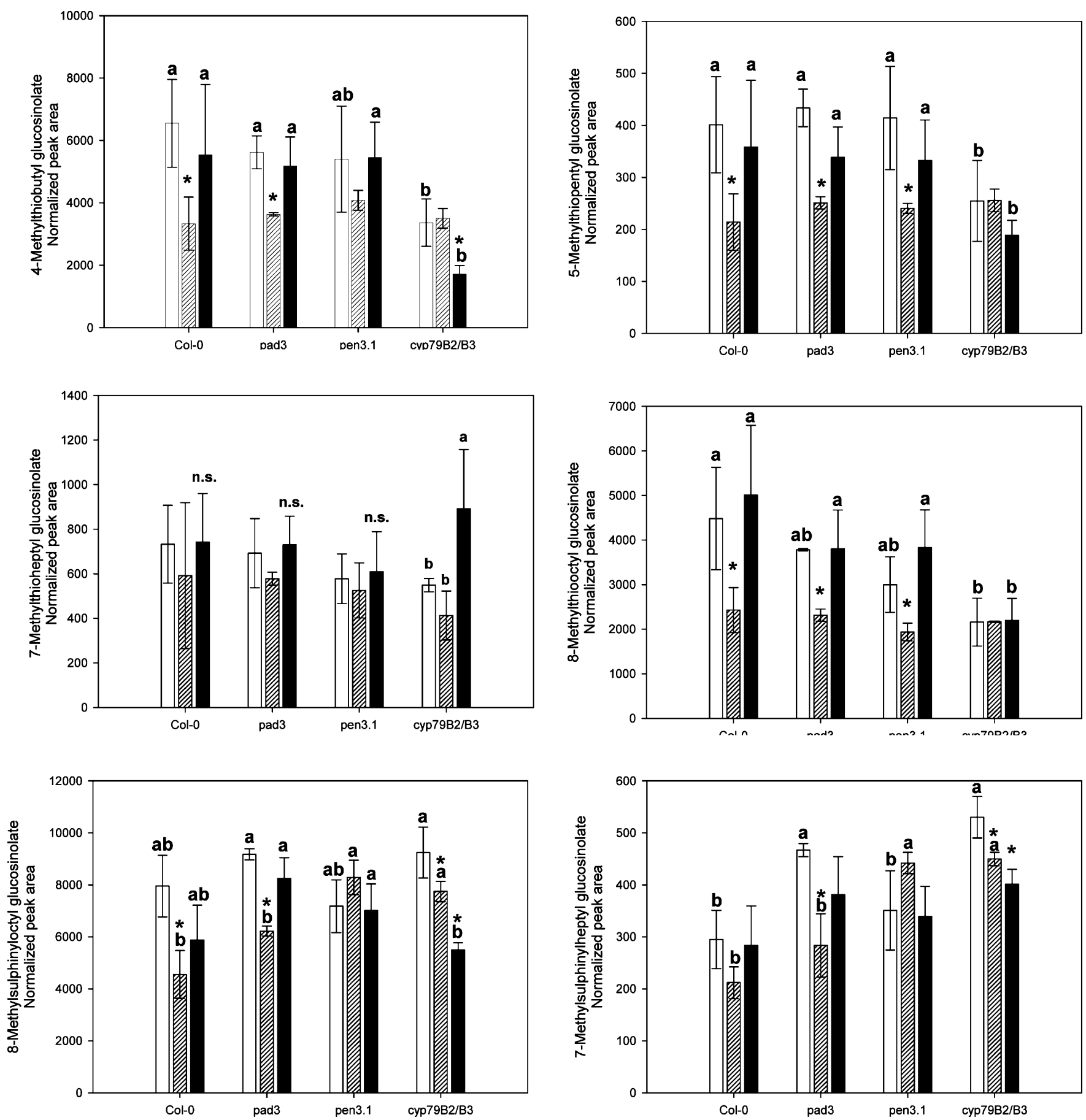

Figure 5. Relative quantitation of aliphatic glucosinolate levels in Arabidopsis rosette leaves in response to abiotic and biotic stresses. White bars represent control plants sprayed with tap water, striped bars represent plants sprayed with a $B$. cinerea conidia suspension, and black bars represent plants sprayed with a $\mathrm{AgNO}_{3}$ solution. Asterisks $(*)$ denote statistical significance at $P \leq 0.05$ with controls. Different letters denote statistical differences among genotypes subjected to the same treatment at $P \leq 0.05$; n.s., not significant.

335 spondingly, camalexin could not be detected either in pad3 or ${ }_{336}$ in cyp79B2/B3 leaf extracts. Nevertheless, a mass chromato337 graphic feature showing a fragmentation pattern compatible 338 with the presence of camalexin, an indolic ring, and neutral 339 losses of $\mathrm{H}_{2} \mathrm{CO}_{2}$ and $\mathrm{C}_{3} \mathrm{H}_{4} \mathrm{O}_{2} \mathrm{~S}$ was observed (Figure 4). This 340 mass chromatographic feature was annotated as dihydrocama${ }_{341}$ lexic acid, the immediate precursor of camalexin and substrate 342 of phytoalexin-deficient-3 (PAD3) protein, by comparison with 343 the reported data in the literature. ${ }^{22}$ This metabolite was strongly accumulated in pad3 plants after stress imposition 344 (Figure 6).

Evaluation of the Stress Treatments. The impact of 346 abiotic and biotic stress treatments on the analytes described 347 above was evaluated after LC/ESI-QTOF-MS analysis. The 348 relative quantitation was carried out first by determining 349 recovery of the internal standard biochanin A (Table 1) to 350 correct areas of target analytes. Finally, corrected peak areas 351 were normalized to the amount of tissue used. Figure 5 shows 352 fs 

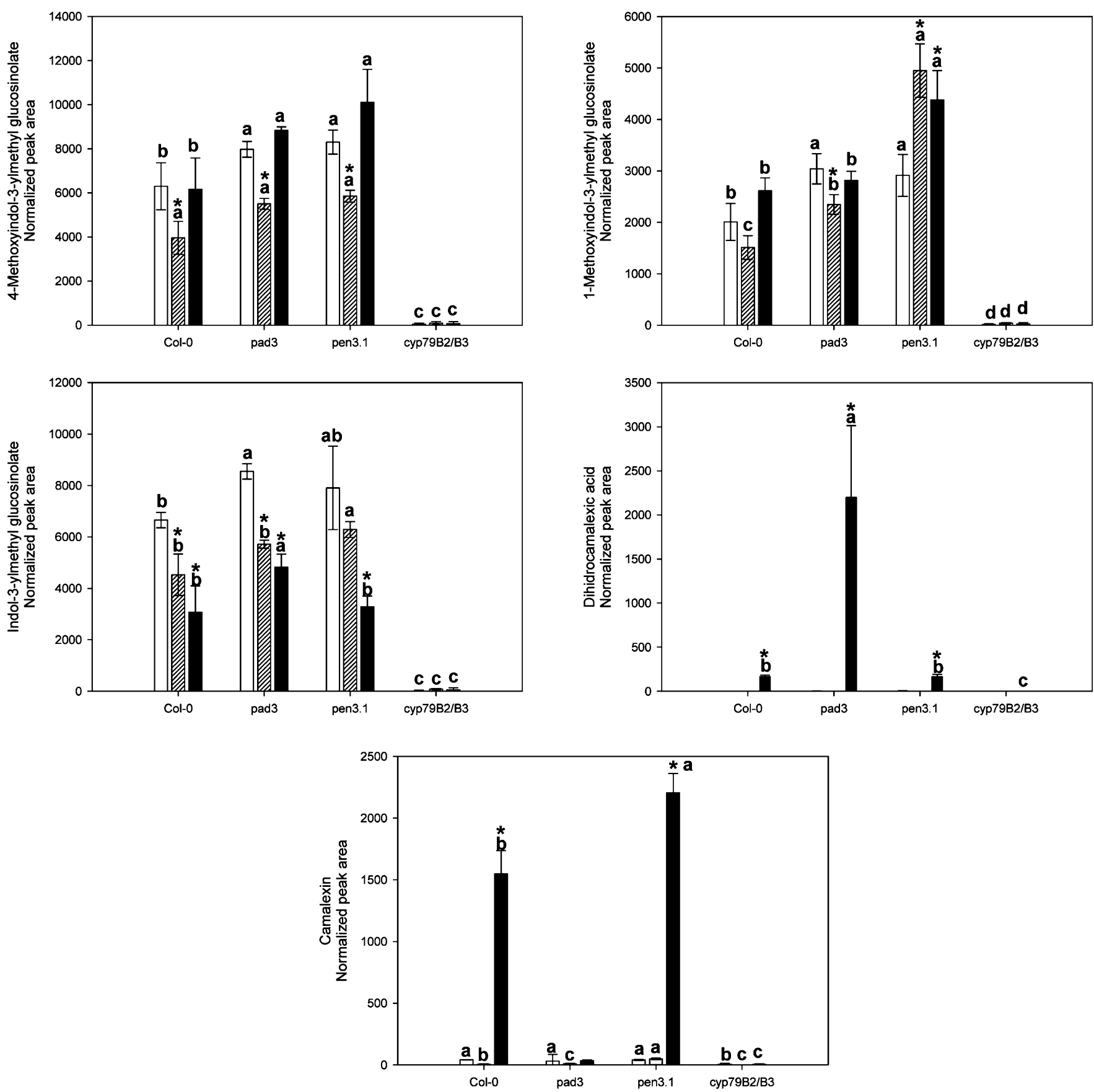

Figure 6. Relative quantitation of indolic glucosinolates, dihydrocamalexic acid and camalexin levels in Arabidopsis rosette leaves in response to abiotic and biotic stresses. White bars represent control plants sprayed with tap water, striped bars represent plants sprayed with a $B$. cinerea conidia suspension, and black bars represent plants sprayed with a $\mathrm{AgNO}_{3}$ solution. Asterisks ${ }^{*}$ ) denote statistical significance at $P \leq 0.05$ with controls. Different letters denote statistical differences among genotypes subjected to the same treatment at $P \leq 0.05$.

353 aliphatic glucosinolate concentrations in the different genotypes 354 under control and stress conditions.

355 First, it should be noted that the different mutations had an 356 effect on basal aliphatic glucosinolate levels. In general, 357 cyp79B2/B3 showed much reduced levels of aliphatics (over $35850 \%$ for 2 and 12 and $40 \%$ for 6 ). Nevertheless, both pad3 and 359 cyp79B2/B3 showed higher basal levels of 3, with respect to 360 Col-0. Spraying Arabidopsis plants with a Botrytis conidia 361 suspension reduced below control levels most aliphatic 362 glucosinolates such as $\mathbf{2}, \mathbf{6}, \mathbf{5}, \mathbf{1 2}$, and 3 in Col-0 and pad3. 363 The mutant pen 3.1, highly sensitive to biotic stress [PEN3 364 encodes for an ATP binding cassette (ABC) transporter involved in the targeted export of toxins to penetration sites], 365 exhibited a slightly different trend, since treatment with the 366 fungus conidia increased $\mathbf{5}$ and 3 levels. In the double mutant, 367 cyp79B2/B3, a different trend for $\mathbf{2 , 6}$, and $\mathbf{1 2}$ was also observed 368 with no significant differences with controls in response to the 369 biotic elicitor. Levels of aliphatic glucosinolates did not 370 significantly vary in Arabidopsis plants treated with $\mathrm{AgNO}_{3} 371$ solution except in the case of cyp79B2/B3 mutants. In this 372 genotype, abiotic stress reduced levels of 2, 6, 5, and 3 and 373 increased the concentration of $\mathbf{1 1}$.

Basal levels of indolic glucosinolates (Figure 6) were $375 \mathrm{f6}$ significantly higher in pad3 and pen 3.1. This could be likely 376 
377 a feedback response to the constitutive absence of camalexin. In 378 addition, an expected result was the complete absence of these 379 metabolites in the cyp79B2/B3 mutant as it is impaired in the 380 activity that catalyzes the conversion of tryptophan to indolic-3381 acetaldoxime (Figure 1). In addition, compounds 13 and 8 382 were absent in these plants after treatment with $\mathrm{AgNO}_{3}$ or 383 Botrytis. Moreover, also as predicted, pad3 mutant failed to 384 accumulate camalexin (13) upon stress treatment but over385 accumulated dihydrocamalexic acid (8), the immediate 386 metabolic precursor of camalexin. ${ }^{28}$ In general, treatment 387 with Botrytis conidia suspension reduced all indolic glucosino388 lates analyzed in Col-0 and pad3, whereas spraying with $\mathrm{AgNO}_{3}$ 389 did not change their levels with respect to controls. On the 390 contrary, in pen 3.1 plants, levels of 9 increased in response to 391 biotic or abiotic elicitors with respect to controls, reflecting its 392 higher sensitivity to both kinds of adverse conditions. ${ }^{20}$ Levels 393 of compound 13 significantly increased upon spraying with $394 \mathrm{AgNO}_{3}$ solution in Col-0 and pen 3.1 mutants, but they did not 395 vary in response to Botrytis treatment. In addition, this 396 metabolite could not be observed in pad3 or cyp79B2/B3 397 mutants. As expected, the dihydrocamalexic acid (8) concen398 tration increased in $\mathrm{AgNO}_{3}$-treated pad3 plants instead (2000399 fold with respect to control values) and to a much lower extent 400 in Col-0 and pen 3.1, directly linking camalexin (13) production 401 to the previous accumulation of dihydrocamalexic acid (8).

402 It has been shown that inoculation of $A$. thaliana with $B$. 403 cinerea conidia reduces both aliphatic and indolic glucosinolate 404 contents. $^{29}$ However, the apparent inconsistency of our data 405 with previous reports showing that $B$. cinerea, a necrotrophic 406 ascomycete, induces camalexin production and accumulation in 407 Arabidopsis can be partially explained by the fact that some $B$. 408 cinerea isolates are camalexin-tolerant and capable of detoxify409 ing this phytoalexin. ${ }^{29}$

410 Differences among Arabidopsis Mutants under Con411 trol Conditions. The complete data set of each Arabidopsis 412 genotype was analyzed by PCA (Figure 7). The first two 413 principal components explained $43.6 \%$ of the total variance in 414 negative mode and $53.0 \%$ in positive mode. As extracted from 415 the PCA plots, principal component 1 (PC1) explained the 416 experimental variation associated with this kind of experiment 417 and clearly differentiated the two biological replicates, whereas 418 PC2 was associated with genotype-specific variation. Hence, 419 PC2 clearly discriminated Col-0, pad3, and pen3.1 genotypes 420 from the cyp $79 B 2 / B 3$ genotype. The similarity among Col-0, 421 pad3, and pen3.1 genotypes allowed us to conclude that the 422 metabolic differences found among these genotypes only 423 appeared after stress imposition. On the contrary, clear basal 424 differences were found between any genotype and the double 425 mutant cyp79B2/B3. This genotype carries insertions in the 426 genes coding for the enzymes that catalyze the conversion of 427 tryptophan to indole-3-acetaldoxime, the first metabolite in the 428 indolic glucosinolates biosynthetic pathway, which also acts as a 429 precursor for camalexin biosynthesis. ${ }^{30}$ To find out which 430 variables (metabolites) were behind these basal differences, a 431 PLS-DA analysis was performed. Among these variables, it was 432 found that indolic glucosinolates were important because they 433 were absolutely absent in cyp79B2/B3 samples, as expected. 434 Strikingly, tryptophan (1) was also found to be important in 435 defining these differences. Relative quantitation of $\mathbf{1}$ in control 436 cyp79B2/B3 was conducted and expressed in Figure 8. The 437 results obtained suggested that as a result of the metabolic 438 deficiency in cytochromes 79B2 and 79B3, the precursor 439 metabolite tryptophan (1) showed an accumulation of 4-fold

\section{A. Negative ionization mode}

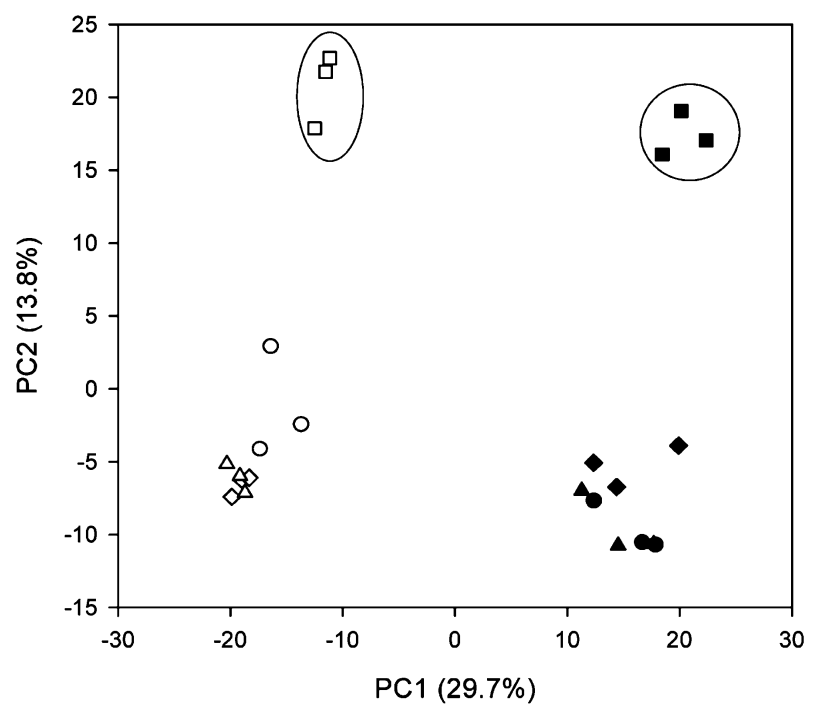

\section{B. Positive ionization mode}

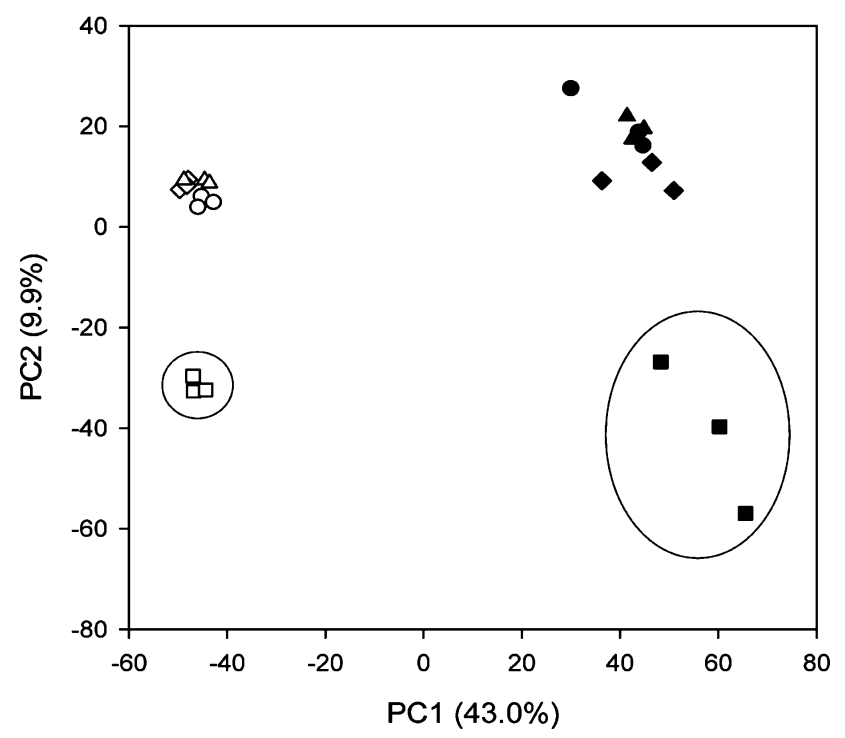

Figure 7. PCA of data sets belonging to Arabidopsis Col-0 (wild type) and cyp79B2/B3, pad3, and pen3.1 mutant leaf extracts under control conditions. Plots represent the PCA analysis in negative (A) and positive (B) ionization modes. Symbols in black and white belong to Arabidopsis accessions in replicates 1 and 2, respectively. Refer to Col$0(\bigcirc)$, cyp79B2/B3 $(\square)$, pad3 $(\diamond)$, and pen3.1 $(\triangle)$. Circles indicate cyp79B2/B3 sample groups in both negative and positive modes and in the two biological replicates.

with respect to the rest of genotypes included in this study. 440 These results also suggested that no negative feedback 441 mechanism prevented tryptophan from accumulating in leaf 442 rosettes of cyp79B2/B3 plants. In addition, no specific 443 phenotype was observed (data not shown): leaf rosette and 444 inflorescence phenotype as well as development were identical 445 to that of Col-0 wild type, indicating that tryptophan 446 overaccumulation had no negative effects on plant perform- 447 ance. $^{24}$ 


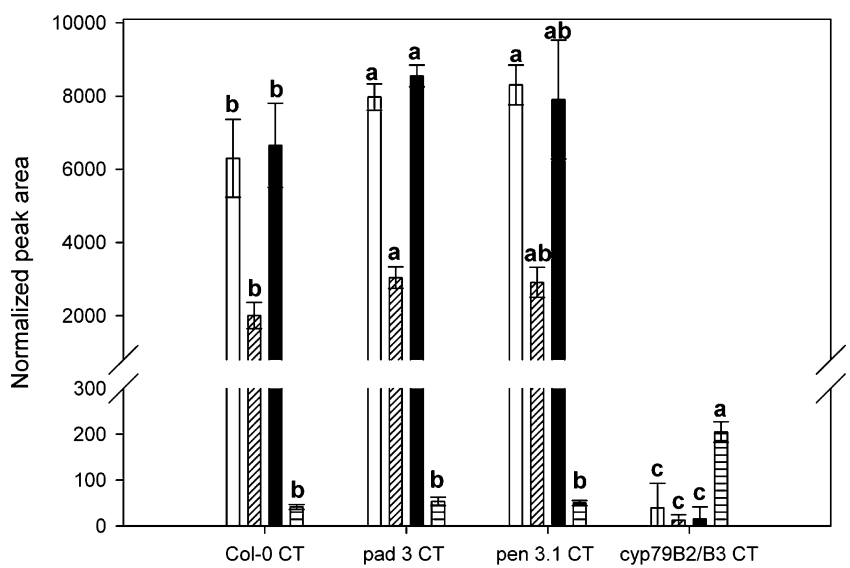

Figure 8. Relative quantitation of tryptophan and indolic glucosinolate levels in Arabidopsis rosette leaves under control conditions. White bars represent compound 7 levels, bars with diagonal lines represent compound 9 levels, black bars represent compound 4 levels, and bars with horizontal lines represent compound 1 levels. Different letters denote statistical differences among genotypes subjected to the same treatment at $P \leq 0.05$.

449 Overall, data presented in this work confirm the use of 450 reversed phase liquid chromatography coupled to QTOF-MS 451 as a useful methodology to profile semipolar compounds in 452 plant extracts, especially glucosinolates and other defense453 related compounds. In addition, the use of mutants carrying 454 alterations in certain biosynthetic pathways in combination with 455 mass spectrometry could be useful in the unequivocal 456 identification of compounds for which commercial standards 457 are unavailable. Both the inoculation with $B$. cinerea conidia and 458 the treatment with a $\mathrm{AgNO}_{3}$ solution have an effect on 459 secondary metabolism but not in the same direction, whereas 460 the biotic elicitor depresses glucosinolate content without any 461 direct effect on camalexin production, the abiotic stress 462 treatment does not alter aliphatic or indolic glucosinolate 463 contents but induces the accumulation of the phytoalexin 464 camalexin. In addition, the impairment in PEN3 (PDR8) ATP465 binding cassette transporter in the mutant pen 3.1 has a positive 466 effect on indolic glucosinolate and camalexin contents in 467 response to biotic or abiotic elicitation and even in nonstressed 468 plants, pointing out to the higher sensitivity of this genotype to 469 stress. Finally, the impairment in cytochrome P79 enzyme 470 activity seems to induce specific alterations in secondary 471 metabolite composition even under nonstressful condition 472 (such as the accumulation of tryptophan). Therefore, because 473 the basal metabolic configuration is different to Col-0, their 474 comparison in genetic and physiological studies should be 475 taken with caution.

\section{ASSOCIATED CONTENT}

\section{S Supporting Information}

478 Table of chromatographic columns tested and characteristics 479 and number of peaks collected in the two gradients used and 480 figure of total ion current chromatograms of plant extracts for 481 the different columns and gradients assayed in this study. This 482 material is available free of charge via the Internet at http:// 483 pubs.acs.org.

\section{AUTHOR INFORMATION}

Corresponding Author

485

*Tel: +34 96472 8101. Fax: +34 96472 8216. E-mail: vicente. 486 arbona@camn.uji.es.

Funding

488

This work was supported by the Spanish Ministerio de 489 Economía y Competitividad (MINECO) and Universitat 490 Jaume I/Fundació Bancaixa through Grant Nos. AGL2010- 491 22195-C03-01/AGR and P11B2009-01, respectively. V.A. was 492 the recipient of a "Ramón y Cajal" contract from the MINECO. 493

Notes

494

The authors declare no competing financial interest.

495

\section{ACKNOWLEDGMENTS}

496

Seeds of cyp79B2/B3, pad3, and pen 3.1 mutants were a kind 497 gift of Christoph Böttcher from the Leibniz-Institut für 498 Pflanzenbiochemie (Halle/Salle). Mass spectrometry analyses 499 were performed at the central facilities (Servei Central 500 d'Instrumentació Cientifica, SCIC) of Universitat Jaume I. $\quad 501$

\section{ABBREVIATIONS USED}

502

PCA, principal component analysis; PLS-DA, partial least- 503 squares discriminant analysis

\section{REFERENCES}

505

(1) Avin-Wittenberg, T.; Tzin, V.; Angelovici, R.; Less, H.; Galili, G. 506 Deciphering energy-associated gene networks operating in the 507 response of Arabidopsis plants to stress and nutritional cues. Plant J. 508 2012, 70, 954-966.

509

(2) Lehmann, M.; Laxa, M.; Sweetlove, L. J.; Fernie, A. R.; Obata, T. 510 Metabolic recovery of Arabidopsis thaliana roots following cessation of 511 oxidative stress. Metabolomics 2012, 8, 143-153.

(3) Arbona, V.; Marco, A. J.; Iglesias, D. J.; Lopez-Climent, M. F.; 513 Talon, M.; Gomez-Cadenas, A. Carbohydrate depletion in roots and 514 leaves of salt-stressed potted Citrus clementina L. Plant Growth Regul. 515 2005, 46, 153-160.

(4) Arbona, V.; Argamasilla, R.; Gómez-Cadenas, A. Common and 517 divergent physiological, hormonal and metabolic responses of 518 Arabidopsis thaliana and Thellungiella halophila to water and salt 519 stress. J. Plant Physiol. 2010, 167, 1342-1350.

(5) Schenke, D.; Böttcher, C.; Scheel, D. Crosstalk between abiotic 521 ultraviolet-B stress and biotic (flg22) stress signalling in Arabidopsis 522 prevents flavonol accumulation in favor of pathogen defence 523 compound production. Plant Cell Environ. 2011, 34, 1849-1864. 524

(6) Ahuja, I.; Kissen, R.; Bones, A. M. Phytoalexins in defense against 525 pathogens. Trends Plant Sci. 2012, 17, 73-90.

(7) Kerchev, P. I.; Fenton, B.; Foyer, C. H.; Hancock, R. D. Plant 527 responses to insect herbivory: Interactions between photosynthesis, 528 reactive oxygen species and hormonal signalling pathways. Plant Cell 529 Environ. 2012, 35, 441-453.

(8) Pollastri, S.; Tattini, M. Flavonols: Old compounds for old roles. 531 Ann. Bot. 2011, 108, 1225-1233.

(9) Arbona, V.; Iglesias, D. J.; Talón, M.; Gómez-Cadenas, A. Plant 533 phenotype demarcation using nontargeted LC-MS and GC-MS 534 metabolite profiling. J. Agric. Food Chem. 2009, 57, 7338-7347. 535

(10) Agerbirk, N.; De Vos, M.; Kim, J. H.; Jander, G. Indole 536 glucosinolate breakdown and its biological effects. Phytochem. Rev. 537 2009, 8, 101-120.

(11) Malitsky, S.; Blum, E.; Less, H.; Venger, I.; Elbaz, M.; Morin, S.; 539 Eshed, Y.; Aharoni, A. The transcript and metabolite networks affected 540 by the two clades of Arabidopsis glucosinolate biosynthesis regulators. 541 Plant Physiol. 2008, 148, 2021-2049.

(12) Grubb, C. D.; Abel, S. Glucosinolate metabolism and its control. 543 Trends Plant Sci. 2006, 11, 89-100. 
545 (13) Agerbirk, N.; Olsen, C. E.; Sørensen, H. Initial and final 546 products, nitriles, and ascorbigens produced in myrosinase-catalyzed 547 hydrolysis of indole glucosinolates. J. Agric. Food Chem. 1998, 46, 548 1563-1571.

549 (14) Brown, P. D.; Tokuhisa, J. G.; Reichelt, M.; Gershenzon, J. 550 Variation of glucosinolate accumulation among different organs and 551 developmental stages of Arabidopsis thaliana. Phytochemistry 2003, 62, $552471-481$.

553 (15) Kliebenstein, D. J.; Kroymann, J.; Brown, P.; Figuth, A.; 554 Pedersen, D.; Gershenzon, J.; Mitchell-Olds, T. Genetic control of 555 natural variation in Arabidopsis glucosinolate accumulation. Plant 556 Physiol. 2001, 126, 811-825.

557 (16) Mewis, I.; Appel, H. M.; Hom, A.; Raina, R.; Schultz, J. C. Major 558 signaling pathways modulate Arabidopsis thaliana (L.) glucosinolate 559 accumulation and response to both phloem feeding and chewing 560 insects. Plant Physiol. 2005, 138, 1149-1162.

561 (17) Kim, J. H.; Jander, G. Myzus persicae (green peach aphid) 562 feeding on Arabidopsis induces the formation of a deterrent indole 563 glucosinolate. Plant J. 2007, 49, 1008-1019.

564 (18) Von Roepenack-Lahaye, E.; Degenkolb, T.; Zerjeski, M.; Franz, 565 M.; Roth, U.; Wessjohann, L.; Schmidt, J.; Scheel, D.; Clemens, S. 566 Profiling of Arabidopsis secondary metabolites by capillary liquid 567 chromatography coupled to electrospray ionization quadrupole time568 of-flight mass spectrometry. Plant Physiol. 2004, 134, 548-559.

569 (19) Glauser, G.; Schweizer, F.; Turlings, T. C. J.; Reymond, P. Rapid 570 profiling of intact glucosinolates in Arabidopsis leaves by UHPLC571 QTOFMS using a charged surface hybrid column. Phytochem. Anal. $5722012,23,520-528$.

573 (20) Stein, M.; Dittgen, J.; Sánchez-Rodríguez, C.; Hou, B.; Molina, 574 A.; Schulze-Lefert, P.; Lipka, V.; Somerville, S. C. Arabidopsis PEN3/ 575 PDR8, an ATP binding cassette transporter, contributes to nonhost 576 resistance to inappropriate pathogens that enter by direct penetration. 577 Plant Cell. 2006, 18, 731-746.

578 (21) Tsuji, J.; Zook, M.; Somerville, S. C.; Last, R. L.; 579 Hammerschmidt, R. Evidence that tryptophan is not a direct 580 biosynthetic intermediate of camalexin in Arabidopsis thaliana. Physiol. 581 Mol. Plant Pathol. 1993, 43, 221-229.

582 (22) Böttcher, C.; Westphal, L.; Schmotz, C.; Prade, E.; Scheel, D.; 583 Glawischnig, E. The multifunctional enzyme CYP71B15 (PHYTOA584 LEXIN DEFICIENT3) converts cysteine-indole-3-acetonitrile to 585 camalexin in the indole-3-acetonitrile metabolic network of Arabidopsis 586 thaliana. Plant Cell. 2009, 21, 1830-1845.

587 (23) Glazebrook, J.; Ausubel, F. M. Isolation of phytoalexin-deficient 588 mutants of Arabidopsis thaliana and characterization of their 589 interactions with bacterial pathogens. Proc. Natl. Acad. Sci. U.S.A. 590 1994, 91, 8955-8959.

591 (24) Zhao, Y.; Hull, A. K.; Gupta, N. R.; Goss, K. A.; Alonso, J.; 592 Ecker, J. R.; Normanly, J.; Chory, J.; Celenza, J. L. Trp-dependent 593 auxin biosynthesis in Arabidopsis: Involvement of cytochrome P450s 594 CYP79B2 and CYP79B3. Genes Dev. 2002, 16, 3100-3112.

595 (25) Muckenschnabel, I.; Goodman, B. A.; Williamson, B.; Lyon, G. 596 D.; Deighton, N. Infection of leaves of Arabidopsis thaliana by Botrytis 597 cinerea: Changes in ascorbic acid, free radicals and lipid peroxidation 598 products. J. Exp. Bot. 2002, 53, 207-214.

599 (26) http://metlin.scripps.edu/download/.

600 (27) Ibañez, M.; Sancho, J. V.; Pozo, O. J.; Niessen, W.; Hernández, $601 \mathrm{~F}$. Use of liquid chromatography quadrupole time-of-flight mass 602 spectrometry in the elucidation of transformation products and 603 metabolites of pesticides. Diazinon as a case study. Rap. Commun. Mass 604 Spectrom. 2006, 384, 169-178.

605 (28) Glawischnig, E. Camalexin. Phytochemistry 2007, 68, 401-406. 606 (29) Kliebenstein, D. J.; Rowe, H. C.; Denby, K. J. Secondary 607 metabolites influence Arabidopsis/Botrytis interactions: Variation in 608 host production and pathogen sensitivity. Plant J. 2005, 44, 25-36. 609 (30) Glawischnig, E.; Hansen, B. G.; Olsen, C. E.; Halkier, B. A. 610 Camalexin is synthesized from indole-3-acetaldoxime, a key branching 611 point between primary and secondary metabolism in Arabidopsis. Proc. 612 Natl. Acad. Sci. U.S.A. 2004, 101, 8245-8250. 